\section{Fórum: legitimidade, expansão e sustentabilidade das Ciências Sociais e Humanas em Saúde Coletiva. Posfácio}

\author{
Forum: legitimacy, expansion, and sustainability \\ of Social and Human Sciences in Public Health. \\ Postscript
}

\section{Ciências Sociais em Saúde: construindo e consolidando um campo}

Num momento de franco desenvolvimento in ternacional das ciências sociais em saúde, a elaboração de um fórum nacional que trate do tema é da mais relevante importância. Minhas preocupações atuais, pesquisando a construção da identidade desse campo entre nós ${ }^{1}$, encontram nos textos propostos ao debate a comprovação de que os caminhos foram abertos, mas necessitamos de uma vigilância permanente no ensino, na produção científica, na divulgação do conhecimento e na relação com as práticas sociais. Estar presente nesse debate é muito honroso, e poder dialogar com diferentes gerações de pesquisadores traz a sensação da vitalidade de um campo cuja institucionalização está completando cinco décadas.

Dos desafios dos anos 60 aos dias atuais, as experiências com o ensino de graduação, primeiramente na medicina, e depois na formação de outros profissionais de saúde, na medida em que trabalhar em equipe tornou-se prática corrente, foram acumuladas e evidenciaram que a biomedicina não pode sozinha dar conta da complexidade dos fenômenos saúde, doença e cuidado. Nesse sentido, o instrumental sociológico tem a possibilidade de ser usado tanto para o ensino na clínica como na comunidade, tanto no hospital como nos serviços públicos de saúde, tanto para a epidemiologia como para a gestão de serviços.
Everardo Duarte Nunes 1

O que não pode ocorrer é a vulgarização e banalização do social. Conservar o rigor teórico e conceitual é fundamental. Isso se aplica a todos os níveis de ensino - da graduação à pós-graduação. Maria Cecília de Souza Minayo 2, de forma sintética, mas com precisão, aborda o tema e faz interessantes sugestões. Concordo que não se pode isolar o ensino das ciências sociais dos problemas contemporâneos e acrescento, tanto no plano local como no internacional. Concordo, também, que apesar dos avanços nos campos teórico e metodológico, o ensino necessita ser revisitado. Ou seja, no passado houve muitas tentativas de inovar, por exemplo, a adaptação da história natural da doença para uma história social, ou de acompanhar a "carreira do doente/paciente" a fim de reconstituir a sua história pessoal, familiar e social, mais aderentes a uma "sociologia na medicina", ou com base em aspectos macroanalíticos (estrutura social, sistema social), mais próximos de uma "sociologia da medicina”. Certamente, estamos num momento em que o ensino precisa rever as suas formas e criar estratégias que possibilitem ao estudante incorporar em sua formação o básico conceitual da sociologia, da antropologia e da ciência política, na graduação e avançar na pós-graduação o bom uso dos "clássicos" e dos "novos clássicos”. Assim, não se trata apenas de estratégias pedagógicas, mas dos conteúdos a serem transmitidos. Isso nos encaminha para a questão da teoria e da metodologia nas pesquisas em ciências sociais no 
campo da saúde, objeto do terceiro artigo deste fórum, elaborado por Suely Ferreira Deslandes \& Jorge Alberto Bernstein Iriart 3.

Essa questão é tema recorrente para os estudiosos desse campo, sem dúvida, fundamental para a construção da sua "identidade cognitiva". Como apontado por muitos estudiosos, a relação entre as ciências sociais e saúde e a teoria sociológica é crucial para a subdisciplina, inclusive porque é ela que, usualmente, distingue a pesquisa social da saúde dos "estudos socialmente orientados” em campos conexos como saúde pública, saúde coletiva, serviço social, planejamento em saúde. O fato de muitos trabalhos terem caráter aplicado levou, no passado, a se considerar o campo das ciências sociais e saúde como ateórico, e isto é surpreendente, considerando-se que a sociologia médica emerge nos anos 50, com o trabalho de Parsons, essencialmente teórico 4. Assim, considero que o artigo sobre usos teóricos e metodológicos aqui apresentado colabora, de um lado, para o melhor entendimento do suposto caráter ateórico do campo - dos 266 artigos analisados, 124 (46,6\%) definem "claramente sua filiação a um referencial teórico-metodológico", embora não se saiba de forma mais detalhada como o teórico é trabalhado -, de outro lado, ressaltando as fragilidades e insuficiências encontradas na utilização do aparato metodológico (categorias metodológicas, técnicas de pesquisa e de análise) das ciências sociais.

Em 1990, no seminário que a Universidade do Estado do Rio de Janeiro organizou sobre As Ciências Sociais no Brasil, dentre os vários temas abordados, Castro-Santos 5 apontava que o padrão de trabalho dos estudantes de graduação e pós-graduação apresentava uma dupla face: uma que se caracterizava por uma "estreita seletividade dos temas", outra, em que se encontravam as inúmeras formas de recortá-los, o que levava a uma pulverização e não aprofundamento dos mesmos. No mesmo trabalho, Castro-Santos 5 (p. 260-1), ao "evocar a antiga preocupação de Florestan Fernandes 6 sobre os fundamentos empíricos da explicação sociológica", alertava para as duas situações em oposição - trabalhos de pesquisa com forte conotação empírica, mas "sem que se note neles um balizamento conceitual que oriente estrategicamente as próprias tarefas no 'campo' eo próprio esforço de análise, e que permita explicar sociologicamente os fenômenos" e, aqueles trabalhos que "descrevem uma espécie de loop teórico sem jamais se aproximarem do 'solo' empírico". Essas advertências parecem-nos procedentes e precisam ser levadas em consideração quando enfrentamos um campo específico de pesquisas - a produção e construção social da saúde, da doença e do cuidado. Somente lembraria que muitos dos trabalhos elaborados na emergência das ciências sociais em saúde, década de 70, trabalharam densamente a teoria sociológica, como pode ser visto em Pereira 7, utilizando as formulações de Fernandes antes citadas.

Tendo começado os comentários por um trabalho no campo do ensino que se situa como parte da construção da "identidade social" das ciências sócias em saúde, voltamos neste momento a dois outros trabalhos que também concorrem para esta construção. Estamos entendendo que essa identidade "é forjada pelo processo de institucionalização através do qual a disciplina procura se estabilizar do ponto de vista de sua organização" 8 (p. 38) e que, em nosso campo, isto tem sido realizado pelas diversas modalidades de reprodução do saber, pelo ensino, publicação e divulgação e exposição oral e visual nos congressos.

Sem dúvida, como exposto por Maria Lúcia Magalhães Bosi 9, a questão da avaliação acadêmica da produção científica em ciências sociais na saúde coletiva é desafiante, especialmente quando referida às pesquisas qualitativas. Analisa que no padrão vigente predomina o que denomina "produtivismo", ou seja, a quantidade de artigos requeridos aos pesquisadores dentro de modelos de avaliação dessa produção científica que marginaliza formas de pesquisa (pesquisas com metodologias quantitativas), estilos de narrativas (as discursivas) e formas de divulgação (livros). Lembramos que essas análises não se aplicam somente à produção em ciências sócias em saúde, mas vem sendo objeto de estudos sobre o próprio campo das ciências sociais. O último relatório da Organização das Nações Unidas para a Educação, a Ciência e a Cultura (UNESCO) 10 destaca que num processo de internacionalização, em um primeiro momento, esse processo "reduz as divisões do conhecimento das ciências sociais entre diferentes regiões do mundo sem destruir a diversidade" 10 (p. 143), mas quando visto pelos critérios de avaliação da produção (coautoria entre pesquisadores de diferentes países) como também onde são produzidos os periódicos e os artigos, a internacionalização tem sido questionada, pela "estrutura altamente assimétrica de troca”, domínio da América do Norte e Europa Ocidental nas duas últimas décadas, quando analisado por meio do número de publicações conjuntas, o predomínio de citações nos artigos produzidos, sendo que estas regiões foram grandemente favorecidas pela globalização e internacionalização da pesquisa. Outro aspecto referese ao risco da exclusão de "pesquisadores menos favorecidos" dos países em desenvolvimento, em nome de um discurso que aborde "temas de relevância global”, assim como a preferência pelo uso do inglês. Portanto, são extremamente opor- 
tunas as análises feitas por Bosi, quando trata especificamente do campo da saúde, fato que corrobora estudos realizados que salientam, dentre outros aspectos, a "impertinência da avaliação da produção intelectual das Ciências Sociais e Humanas na Saúde Coletiva (CSHSC) segundo o parâmetro do prestígio de periódicos do campo biomédico" 11 (p. 683) e da própria avaliação dos cursos de pós-graduação que com " $a$ hegemonia ou a predominância de critérios, culturas e procedimentos das ciências exatas e naturais, as quais migraram para outras áreas e funcionaram como uma camisa de força" 11 (p. 696), fato reconhecido pela própria Coordenação de Aperfeiçoamento de Pessoal de Nível Superior (Capes) em seu plano decenal - 2011-2020 11 .

Deixamos para o final o artigo de Leny Alves Bonfim Trad 12, que também incluo quando se tenta estabelecer a "identidade social" do campo e que se refere aos congressos. Sem dúvida, essa forma amplia a participação e visibilidade de qualquer campo de conhecimento nacional e internacionalmente e pode possibilitar uma (re)definição de temáticas e redimensionamento do campo. A análise se prende ao V Congresso de Ciências Sociais e Humanas em Saúde, São Paulo, 2011, cujo tema central foi O Lugar das Ciências Sociais na Saúde Coletiva, em especial, sobre a produção científica, veiculada pelos Grupos de Trabalho (GTs). Não se prendendo a todos os aspectos do evento, a autora destaca o que se revela em termos de produção científica e suas tendências quando são analisados 1.482 trabalhos, de 21 GTs. Com exceção de três GTs que optaram por um corte disciplinar (histórico, sociológico) e um sobre aspectos metodológicos, os demais são sobre os mais diversos temas, sendo que os cinco primeiros versam sobre: movimentos sociais e educação popular em saúde, integralidade, mediações sociais e justiça na demanda por cuidado em saúde, humanidades e humanização em saúde, análise de narrativa e experiência de saúde, adoecimento e cuidado e sociologia do campo da análise de políticas públicas e de saúde no Brasil e racionalidades médicas e práticas em saúde. Embora tenha sido apontada a grande diversidade temática, alguns temas não estiveram presentes, como a saúde da população negra, saúde mental, determinantes sociais em saúde e a pequena presença do tema da violência. O texto tem muitos e importantes dados, e o destaque feito é apenas para caracterizar que essa "cartografia" do campo, não somente informa, mas permite estabelecer, na minha opinião, "trajetos do conhecimento" produzidos e vivenciados pelos autores na medida em que puderam apresentar e discutir os achados de pesquisas empíricas e teóricas. De outro lado, permite verificar, comparativamente, com outros congressos a produção científica, não apenas consolidada em publicações, como vimos no artigo de Deslandes \& Iriart, mas em seu movimento - exposição, análise e interação com outros participantes do grupo. As análises feitas pela autora são pertinentes e concordo que hoje essa produção, em um movimento pendular, passe novamente a dar atenção à macroanálise e não apenas às microanálises como foi detectado em $68 \%$ dos trabalhos empíricos.

Certamente, lições antigas como as de Charles Wright Mills 13 ou de Norbert Elias 14 , ou mais recentes como as de Philippe Corcuff 15 não podem ser esquecidas, tanto para pensar o conhecimento como para organizá-lo em próximos eventos. O encontro dos clássicos e dos contemporâneos, como lembrado por Minayo em seu texto, assim como o de aprofundar as relações não somente com a biologia, mas com outras áreas do conhecimento continuam a ser a pauta dos cientistas sociais em saúde.

Os quatro trabalhos apresentados mostram a contemporaneidade do campo das ciências sociais em saúde e se há entraves, há realizações, se há desafios, há perspectivas. Penso que a sua identidade como "campo disciplinar" vem sendo construída. Particularizo a sociologia da saúde, mas estendo a ideia às ciências sociais em geral. Nessa construção à sua "identidade histórica" que pode ser buscada desde as suas "manifestações", para usar a linguagem de Antônio Cândido 16 nos viajantes, naturalistas, folcloristas, médicos-cientistas sociais (Nina Rodrigues, Arthur Ramos, Afrânio Peixoto), cientistas sociais (Donald Pierson, Kalervo Oberg, Roger Bastide, Charles Wagley, Oracy Nogueira, Maynard de Araujo, Armando Piovesan, Luis Fontenelle, Arthur Rios e outros) que associaram seus nomes aos primeiros estudos sobre comunidades, educação sanitária, ciências sociais e saúde pública, pacientes internados, doença mental, incorpora-se a sua "identidade social". Inicialmente, no ensino, depois na participação nos movimentos das reformas sanitárias, nos grupos de pesquisa, nos eventos (encontros, seminários, congressos) as ciências sociais foram forjando formas de atuação nos domínios acadêmico, político-social e nas instituições de saúde (Serviço Único de Saúde e centros de saúde). Sem dúvida, a sua visibilidade e relação com a comunidade científica se constroem no espaço da produção científica - "identidade cognitiva”. Essa se encontra em franco crescimento, tanto na literatura publicada como nas teses e dissertações.

Retomo, para encerrar o que apresentei recentemente, quando disse: "Certamente, como já apontado, a identidade da Sociologia da Saúde 
está sendo construída e, passada a 'fase heróica', enfrentada pelos primeiros cientistas sociais que se aventuraram nesse caminho na fase inicial de institucionalização desse campo, há a necessidade de que se formalizem os canais para a formação das novas gerações de cientistas sociais em saúde, se desenvolvam meios de divulgação da produção científica e se institucionalizem as relações, de um lado, com as matrizes sociológicas e de outro com o campo da saúde" 1 (p. 21).

\section{Referências}

1. Nunes ED. A sociologia da saúde no Brasil: a construção de uma identidade. II Seminário Internacional de Sociologia da Saúde. Campinas: Faculdade de Ciências Médicas, Universidade Estadual de Campinas; 2012.

2. Minayo MCS. Herança e promessas do ensino das Ciências Sociais na área da Saúde. Cad Saúde Pública 2012; 28:2367-72.

3. Deslandes SF, Iriart JAB. Usos teórico-metodológicos das pesquisas na área de Ciências Sociais e Humanas em Saúde. Cad Saúde Pública 2012; 28:2380-6.

4. Cockerham WC. Medical sociology and sociological theory. In: Cockerham WC, editor. The Blackwell Companion to Medical Sociology. Oxford: Blackwell Publishers Ltd.; 2001, p. 3-22.

5. Castro-Santos LA. Alguns dilemas da universidade brasileira e o ensino da sociologia. In: Bomeny $\mathrm{H}$, Birman P, organizadores. As assim chamadas ciências sociais. Rio de Janeiro: Editora RelumeDumará; 1991. p. 251-64.

6. Fernandes F. Fundamentos empíricos da explicação sociológica. São Paulo: Nacional; 1967.

7. Pereira JCM. A explicação sociológica na medicina social. São Paulo: Editora Unesp; 2006.

8. Villas Bôas GK. A tradição renovada. In: Bomeny $\mathrm{H}$, Birman P, organizadores. As assim chamadas ciências sociais. Rio de Janeiro: Editora RelumeDumará; 1991. p. 21-41.
9. Bosi MLM. Produtivismo e avaliação acadêmica na Saúde Coletiva brasileira: desafios para a pesquisa em Ciências Humanas e Sociais. Cad Saúde Pública 2012; 28:2387-92.

10. United Nations Educational, Scientific and Cultural Organization. World social science report: knowledge divides. Paris: United Nations Educational, Scientific and Cultural Organization; 2010.

11. Costa NR. A avaliação da produção intelectual e o declínio da interdisciplinaridade na Saúde Coletiva. Physis (Rio J.) 2012; 22:681-9.

12. Trad LAB. Temas e enfoques contemporâneos nas Ciências Sociais e Humanas no Brasil: expressões e tendências refletidas no $\mathrm{V}$ congresso da área. Cad Saúde Pública 2012; 28:2373-9.

13. Mills CW. A imaginação sociológica. Rio de Janeiro: Editora Zahar; 1959.

14. Elias N. A sociedade dos indivíduos. Rio de Janeiro: Jorge Zahar Editor; 1994.

15. Corcuff P. As novas sociologias: construções da realidade social. São Paulo: Edusc; 2001.

16. Cândido A. formação da literatura brasileira. São Paulo: Itatiaia; 1975.

Recebido em 20/Ago/2012

Aprovado em 30/Ago/2012 